\title{
An oral pathogen and psychopathology severity in a sample of Arab patients with schizophrenia Mohab M. Fawzi ${ }^{\mathrm{a}}$, Hany M. El-Amin ${ }^{\mathrm{a}, \mathrm{c}}$, Maggie M. Fawzi ${ }^{\mathrm{a}}$ and Mahmoud H. El-Affendi ${ }^{\mathrm{b}, \mathrm{d}}$
}

\author{
${ }^{a}$ Faculty of Medicine, Zagazig University, Zagazig, \\ ${ }^{b}$ Department of Prosthodontics, Faculty of Dentistry, \\ Ain Shams University, Cairo, Egypt, ${ }^{\circ}$ Erfan Psychiatric \\ Hospital and ${ }^{d}$ SABA clinic, Jeddah, Saudi Arabia \\ Correspondence to Mohab M. Fawzi, Faculty of \\ Medicine, Zagazig University, Zagazig, Egypt \\ Tel: + 055236 4560; fax: + 0552364284 \\ e-mail: mohabfawzi@yahoo.com \\ Received 13 December 2010 \\ Accepted 15 March 2011 \\ Middle East Current Psychiatry \\ 2011, 18:149-156
}

\section{Background}

Patients with schizophrenia are known to have poor oral health and to die early from cardiovascular disease. It is also known that Porphyromonas gingivalis is a periodontopathogen, which is implicated in a number of systemic diseases, particularly cardiovascular disease. However, little, if any, is known about the prevalence and the quantity of this organism in the mouth of patients with schizophrenia.

\section{Aim}

To estimate the prevalence and quantity of $P$. gingivalis in saliva of patients with schizophrenia compared with nonpsychiatric controls and to correlate the quantity of $P$. gingivalis with the severity of psychopathology of schizophrenia.

\section{Methods}

Forty-three consecutive Arab attendees of the outpatient clinic of a psychiatric Hospital in Jeddah, with a diagnosis of schizophrenia, were assessed by the Positive and Negative Syndrome Scale and the Clinical Global Impression-Severity Scale. They were compared with 43 nonpsychiatric controls, in terms of the prevalence and in terms of the quantity of $P$. gingivalis in their saliva. For this purpose, anerobic culture and real-time polymerase chain reaction (PCR) with a TaqMan probe were used. Results

In 82 (approximately 95\%) participants, the real-time PCR results were matching those obtained with anerobic culture. Using real-time PCR, $P$. gingivalis was detected in 30 (approximately 70\%) patients and in six (approximately 14\%) controls $(P=0.000)$. The $P$. gingivalis median (range) number of copies in salivary samples of patients and controls were $5.6 \times 10^{7}\left(0-2.79^{10}\right)$ and $1.9 \times 10^{5}\left(0-6.84^{7}\right)$, respectively $(P=0.002)$. In addition, the $P$. gingivalis levels were positively correlated with the scores on all the Positive and Negative Syndrome Scale and Clinical Global Impression-Severity Scale.

\section{Conclusion}

Real-time PCR, in keeping with the results of quantitative culture, showed that (i) there is a higher prevalence and quantity of $P$. gingivalis in saliva of a sample of Arab patients with schizophrenia compared with nonpsychiatric controls and (ii) that there is a positive correlation between quantity of $P$. gingivalis cells and the severity of psychopathology of schizophrenia. Hopefully, the results of this pilot study will encourage further research into the relationships between oral microbiota and schizophrenia. Real-time PCR, as demonstrated by this study, is a promising tool in this area. It is also hoped that some preventive dental programs will become an integral part of a comprehensive psychiatric management to meet the need of this vulnerable group of population.

\section{Keywords:}

Clinical Global Impression-Severity Scale, oral health, Porphyromonas gingivalis, Positive and Negative Syndrome Scale, real-time PCR, saliva, schizophrenia

Middle East Curr Psychiatry 18:149-156

(C) 2011 Okasha Institute of Psychiatry, Faculty of Medicine, Ain Shams University 2090-5408

\section{Introduction}

Patients with schizophrenia have poor physical health and high rates of mortality [1-3]. Oral health, which is an integral part of the general health and contributes to self esteem and quality of life, may have a low priority among these patients who are, nevertheless, liable to get dental problems [4]. General self-neglect associated with mental illness, misconceptions, fear of treatment, worry about the cost of treatment, inability to access dental services, and the adverse effects of medications are among the most commonly cited barriers to dental care $[5,6]$.

It has been estimated that more than 700 different bacterial species inhabit the human oral cavity [7]. 
Although the majority of oral microflora are normal/ commensal bacteria, some of them are opportunistic pathogens responsible for the development of oral microbial infectious diseases such as dental caries and periodontitis [8]. One of the most pathogenic species of the entire oral flora and perhaps the most extensively studied species at the molecular level is Porphyromonas gingivalis. This pathogen is frequently found as a prominent component of the flora of subgingival lesions of adult patients with periodontitis [9]. However, $P$. gingivalis not only causes chronic localized oral conditions but may also increase the risk of systemic diseases, such as atherosclerotic heart disease [10].

In patients with periodontitis, $P$. gingivalis can be detected in saliva, on the dorsum of the tongue, tonsils, buccal mucosa, gingiva, and other mucous membranes [11], whereas in periodontally healthy individuals, this organism is usually absent, or if present it is in low numbers [12]. Studies suggest that periodontal disease can be minimized through maintenance of oral cleanliness [13]. However, noncompliance is a major issue [14]. Although it is a universal phenomenon, noncompliance appears to affect people with severe mental illness, such as schizophrenia, considerably more than other people [15]. In these patients, noncompliance is found to be as high with nonpsychiatric drugs as with psychiatric medications [16] and is probably related to the severity of psychopathology $[17,18]$. These patients are further disadvantaged not only by having higher rates of physical illnesses than those without schizophrenia but also by experiencing greater difficulty in obtaining adequate healthcare [19].

To date, however, there has been relatively little research assessing orodental status of patients with schizophrenia. Most of these studies have been published in specialty journals in the field of oral health [4] and have focused on institutionalized chronic patients (for example, [20-22]), although the majority of patients are now living outside hospital. Moreover, approaches have been mostly restricted to a clinical descriptive level using self-report questionnaires (for example, $[5,23,24]$ ) and/or clinical dental examinations (for example, [21,25-27]), with main interest centered around merely counting the number of teeth. It may be rather surprising that, despite the availability and the researchers' extensive use of various procedures to examine oral microorganisms in various populations, no previous attempts have been made, as far as we know, to detect or quantify oral opportunistic pathogens, such as $P$. gingivalis, in patients with schizophrenia. These patients are particularly prone to cardiovascular disease [28], which is the chief cause of their excess premature mortality [29]. Ironically, oral infection with $P$. gingivalis has been also strongly associated with cardiovascular disease, even after adjustment for established cardiovascular risk factors [10]. However, it is not known whether there is any relationship between P. gingivalis and schizophrenia, although researchers have tried, for more than a century, and still trying to find a role for infectious agents in triggering schizophrenia [30].
The aim of this study is to estimate the prevalence and quantity of $P$. gingivalis in saliva of patients with schizophrenia compared with nonpsychiatric controls and to correlate the quantity of $P$. gingivalis with the severity of psychopathology of schizophrenia. We hypothesize that the severity of oral infection in patients with schizophrenia is related to the severity of psychopathology.

\section{Methods}

A total of 43 Arab nationals were recruited from consecutive attendees of the outpatient clinic of a large private psychiatric hospital in Jeddah during the year 2010, with a diagnosis of schizophrenia [F.20 of the International Classification of Diseases tenth revision (ICD-10)]) [31]. The duration of the condition was at least 1 year. The patients' age range was $20-50$ years. Patients were consistently prescribed a stable regimen of antipsychotic medication for at least 3 months before recruitment.

The control group consisted of 43 participants, individually matched for age and sex and randomly selected from companions of patients and from hospital employees and their acquaintances.

None of the participants had current febrile acute infection, acute exacerbation of a chronic infection, or an inflammatory disease, underlying hematologic, malignant, severe cardiac, liver, or renal disease. None had used antibiotics or had undergone any dental or general surgery within the previous 3 months. Participants who had missing teeth and women who were pregnant or lactating were excluded from the study. Body mass index greater than or equal to 35 or less than or equal to 18 and blood pressure of more than 150/90 were also exclusion criteria. Controls had no evidence of current or history of any psychiatric disorder. Written informed consent was obtained from each participant. Patients underwent a standardized psychiatric interview during which the ICD10 diagnosis of schizophrenia was confirmed and two measures were administered by a trained psychiatrist: (i) the Positive and Negative Syndrome Scale (PANSS) [32]. This is a 30-item test, subdivided into three subscales: a Positive Scale composed of seven items, a Negative Scale composed of seven items, and a General Psychopathology Scale composed of 16 items. Each item is rated on a seven-point severity scale from 1 (no evidence) to 7 (extreme). (ii) The Clinical Global Impression-Severity Scale (CGIs) [33]. This subscale of CGI assesses the psychiatrist's impression of the patient's current illness state on a scale ranging from 1 (not ill at all) to 7 (extremely ill).

\section{Saliva sampling procedure}

Saliva specimens were collected by expectoration into sterile calibrated medical cups. Saliva was put into Eppendorf tubes, which were immediately frozen at $-80^{\circ}$ and stored until used in real-time polymerase chain reaction (PCR). For the detection of $P$. gingivalis by 
bacterial culture, saliva samples were pooled in $1.5 \mathrm{ml}$ of reduced transport fluid and were processed for cultivation under anerobic conditions within $4 \mathrm{~h}$ of sampling. Samples were vortexed for $2 \mathrm{~min}$ and split. A total of $100 \mu \mathrm{l}$ of the sample was used for culture by 10 -fold serial dilution in sterile phosphate-buffered saline solution.

\section{Microbial culture}

Serial 10-fold dilutions were prepared, and the last three dilutions were used for plating on blood agar plates (Oxoid, Basingstoke, UK) supplemented with horse blood (5\%; vol/vol), hemin $(5 \mathrm{mg} / \mathrm{l})$, and menadione $(1 \mathrm{mg} / \mathrm{l})$. This was incubated anerobically in jars filled by the evacuation-replacement method with a mixture of gases $\left(85 \% \mathrm{~N}_{2}, 10 \% \mathrm{H}_{2}, 5 \% \mathrm{CO}_{2}\right)$ at $37^{\circ} \mathrm{C}$ for $7-14$ days. The isolates were identified as $P$. gingivalis on the basis of Gram staining, anerobic growth, having the typical colony color and morphology, lacking colony autofluorescence, positive hemagglutination with $3 \%$ sheep erythrocytes, production of a set of metabolic enzymes (as tested with the Rapid ID kit 32A), and having a positive indole reaction. The total number of colony forming unit of P. gingivalis in positive samples was determined.

\section{Real-time polymerase chain reaction \\ Isolation of DNA}

To extract DNA from the bacteria present in saliva, frozen suspensions were thawed and $100 \mu$ of sample was used for automated DNA extraction and for purification with the MagNA Pure DNA Isolation Kit III (Bacteria, Fungi; Roche Molecular Diagnostics, Roche Diagnostics Corporation, Indianapolis, USA). The protocol included $1 \mathrm{~h}$ of pretreatment with proteinase $\mathrm{K}(20 \mathrm{mg} / \mathrm{ml})$ at $56^{\circ} \mathrm{C}$. After isolation, the DNA was eluted in $100 \mu \mathrm{l}$ of elution buffer.

Polymerase chain reaction primers and probes

The 16S rRNA sequences of the genus Porphyromonas were selected. The sequence of the forward primer was 5'-GCGCTCAACGTTCAGCG-3' (basepairs 612-628); the sequence of the reverse primer was $5^{\prime}$-CACGAATTC CGCGTGC-3' (basepairs 664-679); and the sequence of the TaqMan probe was 5'-CACTGAACTCAAGCCCGG CAGTTTCAA-3' (basepairs 634-660) The primers and probes were purchased from Applied Biosystems (Foster City, California, USA).

\section{Quantitative polymerase chain reaction assay}

PCR amplification was performed in a total reaction mixture volume of $25 \mu \mathrm{l}$. The reaction mixtures contained $12.5 \mu \mathrm{l}$ of $2 \times$ TaqMan universal PCR master mixture (PCR buffer, deoxynucleoside triphosphates, AmpliTaq Gold, an internal reference signal (6-carboxy-X-rhodamine), uracil $\mathrm{N}$-glycosylase, $\mathrm{MgCl}_{2}$; Applied Biosystems), $P$. gingivalis-specific primer ( $300 \mathrm{nmol} / \mathrm{l}$ each), P. gingivalisspecific probe $(100 \mathrm{nmol} / \mathrm{l})$, and $5 \mu \mathrm{l}$ of purified DNA from plaque samples. Five microliters of the DNA extracted from $P$. gingivalis W83 was used to prepare the standard curve and as a positive control; the negative control was $5 \mu \mathrm{l}$ of sterile $\mathrm{H}_{2} \mathrm{O}$. The samples were subjected to an initial amplification cycle of $50^{\circ} \mathrm{C}$ for
$2 \mathrm{~min}$ and $95^{\circ} \mathrm{C}$ for $10 \mathrm{~min}$, followed by 45 cycles at $95^{\circ} \mathrm{C}$ for $15 \mathrm{~s}$ and $60^{\circ} \mathrm{C}$ for $1 \mathrm{~min}$.

The degradation of the probe by the DNA polymerase in each elongation step induces an increase in fluorescence that can be monitored during PCR amplification. The fluorescence signal is normalized by dividing the reporter dye emission (6-carboxyfluorescein) by the emission of the passive reference (6-carboxy-X-rhodamine). The higher the starting copy number of the nucleic acid target is, the sooner a significant increase in fluorescence is observed. Hence, this parameter can be used to compare different amplification reactions. The number of bacterial copies was calculated assuming that the genome mass is equal to $2.37 \mathrm{fg}$ (femtogram $=10^{-15} \mathrm{~g}$ ) [34].

\section{Statistical analysis}

Continuous data were expressed as mean [ \pm standard deviation (SD)] or median (range) and were compared using Student's $t$-test, after testing for normality with a Kolmogorov-Smirnov test and after normalization by logtransformation where appropriate. Categorical data were expressed as frequencies or proportions and were analyzed with the two-tailed $\chi^{2}$ test. Correlations between data were analyzed using Pearson's coefficient. Data that significantly correlated with $P$. gingivalis number of copies, after testing for potential collinearity using Pearson's correlations, were further analyzed using stepwise multivariate linear regression analysis with both forward selection and backward elimination $(P<0.05$ for entry and $P>0.10$ for removal). The SPSS statistical program, version 11.5 (SPSS for Windows, 2001, SPSS Inc, Chicago, Illinois, USA) was used for all statistical analyses and for sample size estimation. A two-tailed $P$ value of less than 0.05 was considered significant.

\section{Results}

\section{Background characteristics of participants}

Patients and controls were not different, except that more patients were 'currently smoking' (Table 1).

\section{Severity of psychopathology in the patient group}

Mean $( \pm \mathrm{SD})$ of scores of patients on the standard scales of PANSS and CGIs are given in Table 2.

\section{Prevalence of salivary $\boldsymbol{P}$. gingivalis}

$P$. gingivalis was more prevalent in saliva from patients than controls. P. gingivalis was detected in approximately $70 \%$ (30 of 43) of the patient group but was found only in approximately $14 \%$ (six of 43 ) of the controls (Table 3 ). For either group, no relationship was found between detection of $P$. gingivalis and sex, age, or nationality. However, significant relationships were observed in both groups between $P$. gingivalis detection and being less educated, being in a lower occupational position, being unmarried, being a current smoker, and not being a Miswak user (Table 3). 
Table 1 Background characteristics of participants

\begin{tabular}{|c|c|c|c|}
\hline & Patients $(N=43)$ & Controls $(N=43)$ & Significance \\
\hline \multicolumn{4}{|l|}{ Sex } \\
\hline Male $(n)$ & 25 & 25 & \multirow[t]{2}{*}{$\chi^{2}=0.000 ;$ d.f. $=1 ; P=1.000$} \\
\hline Female $(n)$ & 18 & 18 & \\
\hline \multicolumn{4}{|l|}{ Age (years): } \\
\hline Mean $( \pm S D)$ & $29.7( \pm 8.9)$ & $30.3( \pm 9.0)$ & $T=0.361 ;$ d.f. $=84 ; P=0.719$ \\
\hline Age group: & & & \multirow{3}{*}{$\chi^{2}=0.050 ;$ d.f. $=1 ; P=0.822$} \\
\hline$<30$ years $(n)$ & 28 & 27 & \\
\hline$>30$ years $(n)$ & 15 & 16 & \\
\hline \multicolumn{4}{|l|}{ Nationality: } \\
\hline Saudi $(n)$ & 20 & 21 & \multirow{2}{*}{$\chi^{2}=0.047 ;$ d.f. $=1 ; P=0.829$} \\
\hline Non-Saudi Arab (n) & 23 & 22 & \\
\hline \multicolumn{4}{|l|}{ Education level: } \\
\hline Intermediate or below $(n)$ & 33 & 25 & \multirow[t]{2}{*}{$\chi^{2}=3.389 ;$ d.f. $=1 ; P=0.066$} \\
\hline Above intermediate $(n)$ & 10 & 18 & \\
\hline \multicolumn{4}{|l|}{ Occupation: } \\
\hline Higher $(n)$ & 8 & 15 & \multirow[t]{2}{*}{$\chi^{2}=2.908 ;$ d.f. $=1 ; P=0.088$} \\
\hline Lower $(n)$ & 35 & 28 & \\
\hline \multicolumn{4}{|l|}{ Marital status: } \\
\hline Married $(n)$ & 21 & 27 & \multirow[t]{2}{*}{$\chi^{2}=1.697 ;$ d.f. $=1 ; P=0.193$} \\
\hline Unmarried $^{\mathrm{a}}(n)$ & 22 & 16 & \\
\hline \multicolumn{4}{|l|}{ Currently smoking } \\
\hline Yes $(n)$ & 27 & 15 & \multirow[t]{2}{*}{$\chi^{2}=6.701 ;$ d.f. $=1 ; P=0.010$} \\
\hline No $(n)$ & 16 & 28 & \\
\hline \multicolumn{4}{|l|}{ Miswak ${ }^{\mathrm{b}}$ habitual user: } \\
\hline Yes $(n)$ & 19 & 23 & \multirow{2}{*}{$\chi^{2}=0.745 ;$ d.f. $=1 ; P=0.388$} \\
\hline No $(n)$ & 24 & 20 & \\
\hline
\end{tabular}

${ }^{a}$ Never married, divorced, separated, and widowed.

${ }^{\mathrm{b}}$ Tooth cleaning stick.

\section{Number of $\boldsymbol{P}$. gingivalis cells}

Table 4 shows the results of absolute quantification of $P$. gingivalis cells determined in individual PCR runs. There is a significant difference between the number of $P$. gingivalis cells in salivary samples of patients and controls.

Relationship of the salivary $\boldsymbol{P}$. gingivalis count with the severity of psychopathology in the patient group

The salivary levels of $P$. gingivalis were significantly positively correlated with the scores on all the PANSS subscales. The highest correlation was noted with the negative subscale. $P$. gingivalis count also positively correlated with the CGI score for severity (Table 5).

\section{Comparison between polymerase chain reaction} and culture

Results obtained with real-time PCR were matching those obtained with anerobic culture in $95.3 \%$ of cases

Table 2 Scores of patients on the Positive and Negative Syndrome Scale and Clinical Global Impression-Severity Scale

\begin{tabular}{lc}
\hline Scale & Score \\
\hline PANSS & \\
$\quad$ Total & \\
$\quad$ Mean $( \pm S D)$ & $84.6( \pm 14.9)$ \\
Positive & \\
$\quad$ Mean $( \pm S D)$ & $23.2( \pm 3.2)$ \\
Negative & \\
$\quad$ Mean ( \pm SD) & $24.0( \pm 3.1)$ \\
General psychopathology & \\
$\quad$ Mean ( \pm SD) & $37.5( \pm 9.1)$ \\
CGls & $5.8( \pm 1.1)$ \\
\hline
\end{tabular}

CGI, Clinical Global Impression-Severity Scale; PANSS, Positive and Negative Syndrome Scale; SD, standard deviation.
(32 positive; 50 negative). A two-by-two contingency table summarizes the results (Table 6). P. gingivalis was cultured from $32(37.2 \%)$ of the 86 saliva specimens. All these culture-positive samples were also positive by the real-time PCR assay. In addition, four samples were positive for $P$. gingivalis by the real-time PCR but negative by culture. These samples were thawed and recultured for 14 days. Two of these samples yielded $P$. gingivalis after this prolonged culture. All the 50 culture-negative samples were negative by the PCR assay $(100 \%$ specificity). None $(0 \%)$ of the PCR negatives was found to be culture positive (Table 6).

Further analyses were performed and stepwise forward multivariate regression analysis was conducted for the whole sample $(N=86)$ using the logarithmically transformed number of copies of $P$. gingivalis as the dependent variable and sex, age, nationality, education level, occupation, marital status, current smoking status, Miswak habitual use, and presence/absence of schizophrenia diagnosis as independent variables. The final model that emerged from the stepwise analysis contained only three predictors. In this model, the presence of schizophrenia diagnosis remained significantly correlated with the number of copies of $P$. gingivalis (Table 7).

\section{Discussion}

We believe that this study is the first to report a higher prevalence of the oral pathogen, P. gingivalis, in saliva from patients with schizophrenia than matched nonpsychiatric controls, independent of sex, age, nationality, education level, occupation, marital status, current smoking status, and Miswak habitual use. We used saliva because, as an 
Table 3 Prevalence of $\boldsymbol{P}$. gingivalis by real-time $\mathbf{P C R}^{\mathbf{a}}$

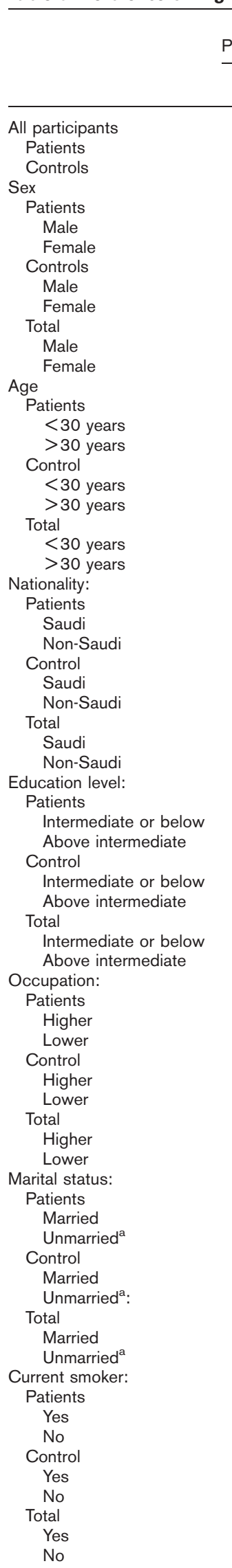

$\begin{array}{ccc}\text { Real-time PCR } & \text { Significance } \\ \text { Positive Negative } & \chi^{2}(\text { d.f. }=1) & P\end{array}$

$N \quad N$

$\begin{array}{rrrr}30 & 13 & 27.520 & 0.000 \\ 6 & 37 & & \\ & & \end{array}$

$\begin{array}{llll}19 & 6 & 1.100 & 0.294 \\ 11 & 7 & & \end{array}$

3

3

22

14

1422

19

11

3

22

14

0.663

$0.225 \quad 0.636$

22$$
\begin{aligned}
& 9 \\
& 4
\end{aligned}
$$

24

24
13
Table 3 (continued)

\begin{tabular}{|c|c|c|c|c|}
\hline & \multicolumn{2}{|c|}{ Real-time PCR } & \multirow{2}{*}{$\begin{array}{l}\text { Significance } \\
\chi^{2}(\text { d.f. }=1)\end{array}$} & \multirow[b]{2}{*}{$P$} \\
\hline & Positive & Negative & & \\
\hline & $N$ & $N$ & & \\
\hline \multicolumn{5}{|c|}{ Miswak ${ }^{\mathrm{b}}$ habitual user } \\
\hline \multicolumn{5}{|c|}{ Patients } \\
\hline Yes & 10 & 9 & 4.739 & 0.029 \\
\hline No & 20 & 4 & & \\
\hline \multicolumn{5}{|c|}{ Control } \\
\hline Yes & 0 & 23 & 8.019 & 0.005 \\
\hline No & 6 & 14 & & \\
\hline \multicolumn{5}{|l|}{ Total } \\
\hline Yes & 10 & 32 & 10.991 & 0.001 \\
\hline No & 26 & 18 & & \\
\hline
\end{tabular}

${ }^{a}$ Number of pareticipants with $P$. gingivalis/Number of participants tested (\%).

${ }^{\mathrm{b}}$ Tooth cleaning stick.

oral circulating fluid, saliva is heavily laden with bacteria (108-109 cfu/ml) [35]. Earlier, all 16S rRNA sequences of the genus Porphyromonas-based saliva studies had used qualitative PCR. For the detection and quantification of $P$. gingivalis in saliva samples in this study, however, we compared the results of a quantitative anaerobic culture method with those of a real-time TaqMan PCR assay, which is, unlike conventional PCR assays, less susceptible to PCR inhibition [36] and is suggested to provide a sensitive, efficient, and reliable approach to quantitation [37]. In keeping with this suggestion, we found the sensitivity, specificity, and positive and negative predictive values of the real-time PCR to be $88.9,100,100$, and 92.6\%, respectively. Therefore, we conclude that realtime PCR confirms the results of quantitative culture of $P$. gingivalis and offers promising advantages with respect to the rapidity and sensitivity of detection of $P$. gingivalis in saliva samples. Until recently, however, very little attention has been given to the quantification of P. gingivalis in saliva, whether of psychiatric or nonpsychiatric populations.

15.282 0.000 Our results demonstrated that in both patients and in controls $P$. gingivalis detection was correlated with being less educated and with being in a lower occupational position. These results are consistent with previous studies, which have shown that periodontitis is more common among people with low rather than with high socioeconomic status, regardless of the indicator used [38]. Interestingly, despite the low socioeconomic level of many of our clients, they probably preferred to attend our private service over the charge-free centers available in the region. Whatever be the reason, it seems that poverty, which raises the risk of schizophrenia, especially deficit schizophrenia [39], might have preferentially reduced the chance of receiving adequate dental care and hence could partly explain our results. However, this study has also shown in the nonpsychiatric controls a somewhat similar trend of association between high prevalence of oral $P$. gingivalis and low educational and occupational levels.

Our finding that the $P$. gingivalis detection was more frequent among unmarried than married people in both patients and controls is also consistent with other studies 
Table 4 Number of copies (median and range values) of $\boldsymbol{P}$. gingivalis in salivary samples of patients and controls assessed by real-time PCR absolute quantification.

\begin{tabular}{lccc}
\hline & Patients & Controls & Significance $^{\mathrm{a}}$ \\
\cline { 2 - 4 } Median (range) & $5.6 \times 10^{7}\left(0-2.79^{10}\right)$ & $1.9 \times 10^{5}\left(0-6.84^{7}\right)$ & $t=3.136 ;$ d.f. $=84 ; P=0.002$ \\
\hline
\end{tabular}

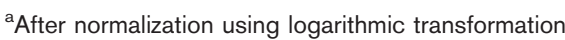

Table 5 Correlation coefficients between number of copies of $P$ gingivalis in salivary samples of patients and scores on the PANSS and CGIs $(\boldsymbol{N}=43)$

\begin{tabular}{lcc}
\hline Scale & $r$ & $P$ \\
\hline PANSS scale & & \\
Total & 0.437 & 0.003 \\
Positive & 0.328 & 0.032 \\
Negative & 0.484 & 0.001 \\
General psychopathology & 0.393 & 0.009 \\
CGls & 0.453 & 0.002 \\
\hline
\end{tabular}

CGI, Clinical Global Impression-Severity Scale; PANSS, Positive and Negative Syndrome Scale.

Table 6 Detection of $P$. gingivalis by real-time PCR and anerobic culture

\begin{tabular}{lccc}
\hline & \multicolumn{2}{c}{ Real-time PCR result ${ }^{\text {a }}$} & \\
\cline { 2 - 3 } Anerobic culture result & Positive $(n)$ & Negative $(n)$ & Total (N) \\
\hline Positive $(n)$ & 32 & 0 & 32 \\
Negative $(n)$ & 4 & 50 & 54 \\
Total $(n)$ & 36 & 50 & 86 \\
\hline
\end{tabular}

${ }^{a}$ Sensitivity $=88.9 \%$; specificity $=100.0 \%$; positive predictive value $=$ $100.0 \%$; negative predictive value $=92.6 \%$.

showing higher susceptibility to various infections among single, widowed, and separated individuals rather than married individuals, independent of other demographic factors [40].

In addition, in keeping with other studies, which have indicated that smoking significantly increases the risk for the development of extensive and severe oral infections [41], we found significant correlation between $P$. gingivalis detection and current smoking in both patients and in controls. In the final model of regression analysis, we found that being a current smoker was the most predictive variable for the level of $P$. gingivalis in saliva.

Interestingly, habitual use of 'Miswak' (the chewing stick or the traditional toothbrush commonly used in Saudi Arabia and many Islamic countries) was negatively associated in this study with $P$. gingivalis detection. This should lend support to the few previous studies, which have suggested that regular use of Miswak is associated with good oral health [42-44].

Correlation coefficients of the salivary levels of $P$. gingivalis with scores on PANSS and CGIs were determined in this study. The results showed that $P$. gingivalis levels were significantly associated with the severity of schizophrenia psychopathology as expressed by scores of both instruments, with negative symptoms presenting the strongest correlation. The achieved results were not unexpected, considering that negative symptoms, which include
Table 7 Stepwise multiple regression analysis of variables significantly related to number of copies of $\boldsymbol{P}$. gingivalis among total participants $(N=86)$

\begin{tabular}{lrcccc}
\hline Variable & $\mathrm{B}$ & $\mathrm{SE}$ & $\beta$ & $t$ & $P$ \\
\hline Constant & 14.790 & 2.093 & & 7.065 & 0.000 \\
Smoker & 3.802 & 1.145 & 0.373 & 3.321 & 0.001 \\
Schizophrenia diagnosis & 3.097 & 0.890 & 0.304 & 3.479 & 0.001 \\
Education & 2.467 & 1.195 & 0.227 & 2.065 & 0.042 \\
\hline
\end{tabular}

Regression analysis included sex, age, nationality, education level occupation, marital status, current smoking status, Miswak habitual use, and schizophrenia diagnosis. $B=$ raw (unstandardized) regression coefficient for the association between stated variables and number of copies of $P$. gingivalis.

Adjusted $R^{2}=0.411 ; F=20.753 ; P=0.000$.

$\mathrm{SE}$, standard error.

symptoms such as lack of initiative (PANSS: N2), apathy, anergy, or avolition (PANSS: N4), etc. would likely lead to reduced self-care and poor dental health, far worse than that of members of the general population [5]. However, a cause and effect relationship between severities of the negative or other symptoms of schizophrenia and quantities of the oral pathogen should not be claimed by this pilot study, at least because of the limitation of its cross-sectional design.

Among participants those with evidence of cardiovascular disease were excluded from the study. However, this variable would have been important and interesting to investigate when relating to both $P$. gingivalis and schizophrenia. Moreover, the study was limited by not reporting some rather relevant data such as details of medication history, general and dental clinical and radiographic examination findings. We did not assess the cognitive functions, although the central role of cognitive dysfunction in schizophrenia has been increasingly appreciated [45], whereas there have been some suggestions that cognitive impairment may be associated with periodontal disease $[46,47]$. Moreover, the endocrine and metabolic status of the participants, despite relevance to both schizophrenia and oral infections with a possible confounding role, were not evaluated. One more limitation is the relatively small sample size.

\section{Conclusion}

Within the limits of this study, we conclude that the realtime PCR has confirmed the results of quantitative culture and has demonstrated significantly higher prevalence and quantity of $P$. gingivalis in the saliva of patients with schizophrenia compared with nonpsychiatric controls. Both real-time PCR and quantitative culture have also confirmed a positive correlation between quantity of $P$. gingivalis cells and severity of psychopathology of schizophrenia. This pilot study may be the first to 
report such findings. It is hoped, however, that the results will encourage further research into the relationships between oral microbiota and schizophrenia. Real-time PCR, with its capacity to produce both qualitative and quantitative results, is a promising tool in this area. We should also hope that the need of the mentally ill for more dental care will be appreciated by all concerned and that some preventive dental programs will become an integral part of comprehensive psychiatric management to meet the need of this vulnerable group of population.

There is no conflict of interest to declare.

\section{References}

1 El Mallakh P, Howard PB, Evans BN. Medical illnesses in people with schizophrenia. Nurs Clin North Am 2010; 45:591-611.

2 Pack S. Poor physical health and mortality in patients with schizophrenia. Nurs Stand 2009; 23:41-45.

3 Von Hausswolff Juhlin Y, Bjartveit M, Lindström E, Jones P. Schizophrenia and physical health problems. Acta Phychiatr Scand Suppl 2009; 438:15-21.

4 Arnaiz A, Zumárraga M, Díez Altuna I, Uriarte JJ, Moro J, Pérez Ansorena MA Oral health and the symptoms of schizophrenia. Psychiatry Res 2010; [Epub ahead of print].

5 McCreadie RG, Stevens H, Henderson J, Hall D, McCaul R, Filik R, et al. The dental health of people with schizophrenia. Acta Psychiatr Scand 2004 110:306-310.

6 Mirza I, Day R, Phelan M, Wulff Cochrane V. Oral health of psychiatric in patients: a point prevalence survey of an inner-city hospital. Psychiatr Bul 2001; 25:143-145.

7 Aas JA, Paster BJ, Stokes LN, Olsen I, Dewhirst FE. Defining the norma bacterial flora of the oral cavity. J Clin Microbiol 2005; 43:5721-5732.

8 Marsh PD, Percival RS. The oral microflora-friend or foe? Can we decide? Int Dent J 2006; 56 (4 Suppl 1):233-239.

9 Loos BG, Dyer DW, Whittam TS, Selander RK. Genetic structure of populations of Porphyromonas gingivalis associated with periodontitis and other oral infections. Infect Immun 1993; 61:204-212.

10 Seymour GJ, Ford PJ, Cullinan MP, Leishman S, Yamazaki K. Relationship between periodontal infections and systemic disease. Clin Microbiol Infect 2007; 13 (Suppl 4):3-10.

11 Van Winkelhoff AJ, Van der Velden U, Clement M, De Graaff J. Intra-ora distribution of black-pigmented bacteroides species in periodontitis patients. Oral Microbiol Immunol 1988; 3:83-85.

12 Griffen AL, Becker MR, Lyons SR, Moeschberger ML, Leys EJ. Prevalence of Porphyromonas gingivalis and periodontal health status. J Clin Microbio 1998; 36:3239-3242.

13 Ciancio S. Improving oral health: current considerations. J Clin Periodontol 2003; 30 (Suppl 5):4-6.

14 Miyamoto T, Kumagai T, Jones JA, Van Dyke TE, Nunn ME. Compliance as a prognostic indicator: retrospective study of 505 patients treated and maintained for 15 years. J Periodontol 2006; 77:223-232.

15 Surguladze S, Timms P, David AS. Teaching psychiatric trainees 'compliance therapy'. Psychiatr Bull 2002; 26:12-15.

16 Dolder CR, Lacro JP, Jeste DV. Adherence to antipsychotic and nonpsychiatric medications in middle-aged and older patients with psychotic disorders. Psychosom Med 2003; 65:156-162

17 Rettenbacher MA, Hofer A, Eder U, Hummer M, Kemmler G, Weiss EM, et al. Compliance in schizophrenia: psychopathology, side effects and patients attitudes toward the illness and medication. J Clin Psychiatry 2004 65:1211-1218.

18 Stanković Z, Britvić D, Vuković O, llle T. Treatment compliance of outpatients with schizophrenia: patient's attitudes, demographic, clinical and therapeutic variables. Psychiatr Danub 2008; 20:42-52.

19 Sartorius N. Physical illness in people with mental disorders. World Psychiatry 2007; 6:3-4.
20 Gurbuz O, Alatas G, Kurt E, Issever H, Dogan F. Oral health and treatment needs of institutionalized chronic psychiatric patients in Istanbul, Turkey. Community Dent Health 2010; 27:151-157.

21 Chu KY, Yang NP, Chou P, Chiu HJ, Chi LY. Factors associated with dental caries among institutionalized residents with schizophrenia in Taiwan: a cross-sectional study. BMC Public Health 2010; 10:482.

22 Zusman SP, Ponizovsky AM, Dekel D, Masarwa AE, Ramon T, Natapov L, et al. An assessment of the dental health of chronic institutionalized patients with psychiatric disease in Israel. Spec Care Dentist 2010; 30:18-22.

23 Hede B, Petersen PE. Self-assessment of dental health among Danish noninstitutionalized psychiatric patients. Spec Care Dentist 1992; 12:33-36.

24 Persson K, Axtelius B, Söderfeldt B, Ostman M. Oral health-related quality of life and dental status in an outpatient psychiatric population: a multivariate approach. Int J Ment Health Nurs 2010; 19:62-70.

25 Gowda EM, Bhat PS, Swamy MM. Dental health requirements for psychiatric patient. MJAFI 2007; 63:328-330.

26 Lewis S, Jagger RG, Treasure E. The oral health of psychiatric in-patients in South Wales. Spec Care Dentist 2001; 21:182-186.

27 Rekha R, Hiremath SS, Bharath S. Oral health status and treatment requirements of hospitalized psychiatric patients in Bangalore city: a comparative study. J Indian Soc Pedod Prev Dent 2002; 20:63-67.

28 Callaghan RC, Boire MD, Lazo RG, McKenzie K, Cohn T. Schizophrenia and the incidence of cardiovascular morbidity: a population-based longitudinal study in Ontario, Canada. Schizophr Res 2009; 115:325-332.

29 Hennekens $\mathrm{CH}$, Hennekens AR, Hollar D, Casey DE. Schizophrenia and increased risks of cardiovascular disease. Am Heart J 2005; 150:1115-1121.

30 Yolken RH, Torrey EF. Are some cases of psychosis caused by microbial agents? A review of the evidence. Mol Psychiatry 2008; 13:470-479.

31 World Health Organization. The ICD-10 classification of mental and behavioural disorders. Geneva: WHO; 1992.

32 Kay SR, Fiszbein A, Opler LA. The positive and negative syndrome scale (PANSS) for schizophrenia. Schizophr Bull 1987; 13:261-276.

33 Guy W. ECDEU assessment manual for psychopharmacology. U.S. National Institute of Health; 1976.

34 Nelson KE, Fleischmann RD, DeBoy RT, Paulsen IT, Fouts DE, Eisen JA, et al. Complete genome sequence of the oral pathogenic bacterium Porphyromonas gingivalis strain W83. J Bacteriol 2003; 185:5591-5601.

35 Gu F, Li Y, Zhou C, Wong DT, Ho CM, Qi F, et al. Bacterial 16S rRNA/rDNA profiling in the liquid phase of human saliva. Open Dent J 2009; 3:80-84.

36 Layton A, McKay L, Williams D, Garrett V, Gentry R, Sayler G. Development of bacteroides 16S rRNA gene TaqMan-based real-time PCR assays for estimation of total, human and bovine fecal pollution in water. Appl Environ Microbiol 2006; 72:4214-4224.

37 Lyons SR, Griffen AL, Leys EJ. Quantitative real-time PCR for Porphyromonas gingivalis and total bacteria. J Clin Microbiol 2000; 38:2362-2365.

38 Borrell LN, Burt BA, Neighbors HW, Taylor GW. Social factors and periodontitis in an older population. Am J Public Health 2004; 94:748-754.

39 Jones BJ, Gallagher BJ III, Pisa AM, McFalls JA Jr. Social class, family history and type of schizophrenia. Psychiatry Res 2008; 159:127-132.

40 Seymour CW, Iwashyna TJ, Cooke CR, Hough CL, Martin GS. Marital status and the epidemiology and outcomes of sepsis. Chest 2010; 137:1289-1296.

41 Shchipkova AY, Nagaraja HN, Kumar PS. Subgingival microbial profiles of smokers with periodontitis. J Dent Res 2010; 89:1247-1253.

42 Al Otaibi M, Zimmerman M, Angmar Mansson B. Prevailing oral hygiene practices among urban Saudi Arabians in relation to age, gender and socioeconomic background. Acta Odontol Scand 2003; 61:212-216.

43 Asadi SG, Asadi ZG. Chewing sticks and the oral hygiene habits of the adult Pakistani population. Int Dent J 1997; 47:275-278.

44 Darout IA, Albandar JM, Skaug N. Periodontal status of adult Sudanese habitual users of miswak chewing sticks or toothbrushes. Acta Odontol Scand 2000; 58:25-30

45 Nuechterlein KH, Green MF, Kern RS. Schizophrenia as a cognitive disorder: recent approaches to identifying its core cognitive components ti aid treatment development. Adv Schizophr Res 2009; 4:267-282.

46 Kaye EK, Valencia A, Baba N, Spiro A III, Dietrich T, Garcia RI. Tooth loss and periodontal disease predict poor cognitive function in older men. J Am Geriatr Soc 2010; 58:713-718.

47 Noble JM, Borrell LN, Papapanou PN, Elkind MS, Scarmeas N, Wright CB. Periodontitis is associated with cognitive impairment among older adults: analysis of NHANES-III. J Neurol Neurosurg Psychiatry 2009; 80:1 206-1211. 


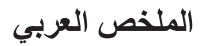

جرثومة بالفم وشدة السيكوباثولوجيا في عينة من مرضى عرب لايهم فصام

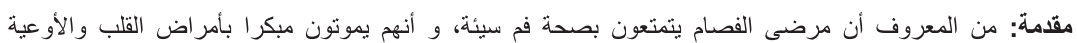

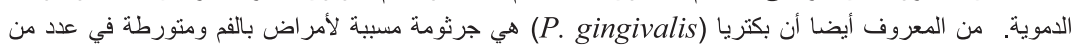

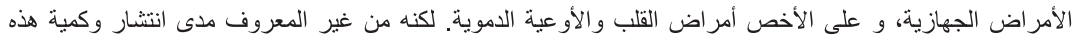

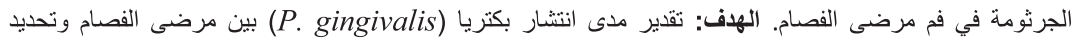

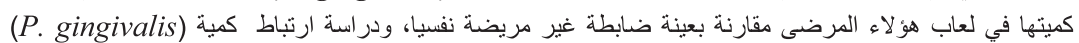

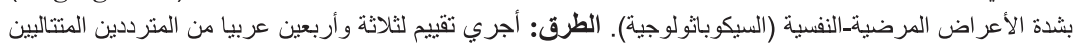

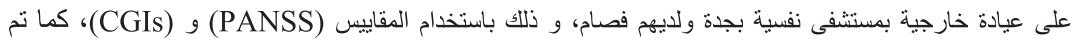

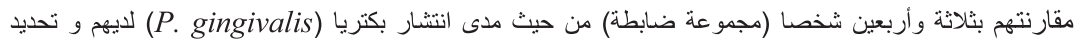

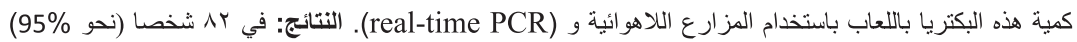

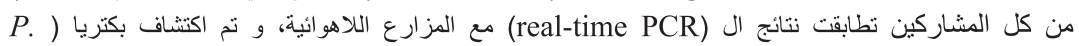
(gingivalis

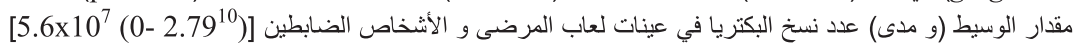

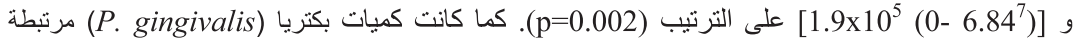

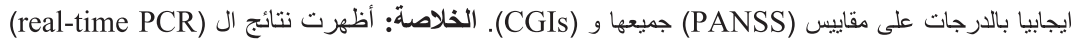

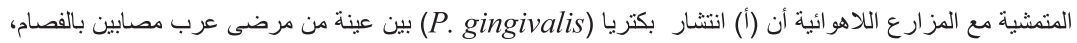

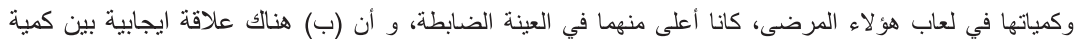

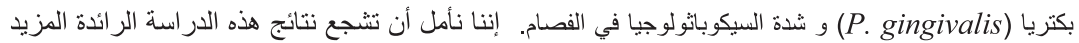

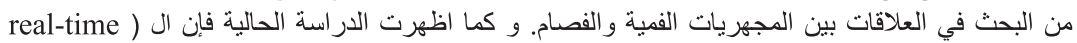

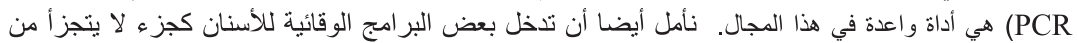

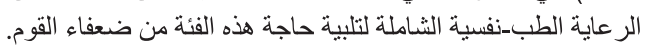

